Trinity University

Digital Commons @ Trinity

Psychology Faculty Research

Psychology Department

$12-2020$

\title{
Everyday Challenges to the Practice of Desirable Difficulties: Introduction to the Forum
}

Paula T. Hertel

Trinity University, phertel@trinity.edu

Follow this and additional works at: https://digitalcommons.trinity.edu/psych_faculty

Part of the Psychology Commons

Publication Details

Journal of Applied Research in Memory and Cognition

\section{Repository Citation}

Hertel, P. (2020). Everyday challenges to the practice of desirable difficulties: Introduction to the forum. Journal of Applied Research in Memory and Cognition, 9(4), 425-427. http://doi.org/10.1016/ j.jarmac.2020.09.002

This Pre-Print is brought to you for free and open access by the Psychology Department at Digital Commons @ Trinity. It has been accepted for inclusion in Psychology Faculty Research by an authorized administrator of Digital Commons@ Trinity. For more information, please contact jcostanz@trinity.edu. 
Everyday Challenges to the Practice of Desirable Difficulties:

Introduction to the Forum

Paula Hertel

Trinity University

Keywords: desirable difficulties, learning, motivation

DOI: 10.1016/j.jarmac.2020.09.002

Journal of Applied Research in Memory and Cognition, 9, 425-427. 
Everyday Challenges to the Practice of Desirable Difficulties:

Introduction to the Forum

When I started teaching, like others I tried to use methods that would improve learning. My exams and other assignments were partly informed by what I knew about memory and cognition, and they were partly motivated by a disdain for teaching as ticket punching. Imagine my enthusiasm, a few years later, in finding empirical support for the application of cognitive psychology to teaching, along with a framework called "desirable difficulties" (Bjork, 1994). The claim, in very general terms, is that features of tasks or situations that make learning more difficult in the short run are desirable features if they benefit performance in the long run. Many applied experiments ensued subsequently. This year, to finish my term as editor of JARMAC, I asked contributors to this forum to address the next set of problems to solve in the application of desirable difficulties to real-world settings. ${ }^{1}$ Some essays in this collection describe practice-oriented challenges and successes; others tell us more about where research must be focused in the future to deliver on the promise inherent in the approach. Robert and Elizabeth Bjork comment on these essays, not just as originators of the approach but as continuing active investigators.

The contributors to the forum each address the barriers to implementing desirably difficult practices. In the first contribution, those barriers are vividly illustrated in the essay by Schulze (2020). Summoning up images from The Paper Chase $^{2}$ for those of us old enough to have seen the series, the archaic approach to learning law is the backdrop for Schulze and his

\footnotetext{
1 The contributors vary in how explicitly they address the central question of what makes a difficulty desirable, which is a teleological problem to many who consider it. From a practical point of view, bootstrapping is sufficient. If the difficulty produces desirable outcomes in certain settings, then it can be exported to similar settings.

2 The Paper Chase ( ( ) Houghton Mifflin, 1971) is a novel written by John Jay Osborn, Jr., a 1970 graduate of Harvard Law School. It was adapted into a television series in the late ' 70 s and early ' 80 s.
} 
colleague's very impressive achievements in training students to do well on law-school and bar exams in Florida. They face on a large scale the resistance that many educators experience in the classroom but, fortunately, they have developed (and plan to improve) a system for implementation that is beyond the average instructor's control.

Working outside the control of the individual educator is sometimes possible, and desirable when educators lack awareness of the evidence for desirably difficult procedures. In the field of mathematics education, for example, textbook writers can rearrange chapter problems to promote interleaving and spacing (Rohrer \& Hartwig, 2020, in the second contribution). Other obstacles, however, are less easily finessed, such as the disregard for evidence-based teaching found in some education journals (or possibly the high regard for neuroscience as the "go-to" route to understanding learning). But for Rohrer and Hartwig, the fundamental barriers to implementation of the practice of interleaving and spacing in mathematics education sits firmly in learners' prior beliefs and their current dislike or fear of short-term difficulties. Such attitudes and beliefs, of course, are shared by many teachers.

In math education and other areas, teachers and students alike do not seem to understand the crutch function of undesirable easiness and prefer to hang onto illusions of skill, reinforced by past short-term achievements. Biwer, De Bruin, Schreurs, and oude Egbrink (2020) give us examples as they report the challenges revealed by their Study Smart program at Maastricht University. Among the ideas emerging from the program is the use of change detection (noticing the difference between the old and the new strategy) as a possible facilitator of switching to newer approaches. This suggestion has a lot in common with laboratory evidence that noticing the relation to prior responses during new learning can aid memory for the new replacements (see Wahlheim \& Jacoby, 2013.) Given sufficient structural control, we might use suggestions 
like these to develop programs that apply other research on change, such as bias modification procedures, or that simulate successful behavioral interventions to avoid the renewal of old habits. Regardless, progress is likely to be slow, given the power of the first thing learned (Bouton, 2000), unless we initiate the training of useful strategies very early, developmentally. In fact, the essay by Knabe and Vlach (2020) reports progress in the study of spaced learning by very young children. These investigators argue more generally for a developmental approach that is necessarily responsive to individual experience (a point of view reminiscent of behavioral interventions). Once again, however, what about the worries and objections of the teachers these children will encounter — teachers who believe they must see payoffs in immediate practice? (Will there be an industry to promote desirably difficult practices during in-service days in the schools? Who will design and watch over it?)

The inevitable uneasiness in abandoning crutches in favor of new methods is one motivational factor that confounds the application of desirably difficult practices. Motivation provides a major theme across all contributions to the forum, and motivational confounds to implementing desirably difficult practices abound to the extent that we lack control of real-world contingencies. Our lack of control is why we want to begin early with young children or design university- or school-wide programs. The problem with relying on course instructors or classroom teachers to implement desirable practices is that other considerations can govern how they teach (e.g., course evaluations; see Bjork, 1994; Carpenter, Witherby, \& Tauber, 2020). And if implementation is entirely under the control of the student, well, the student will respond to all the approval contingencies and motives we have set in place over the centuries of teaching them (see also Finn, 2020). So, to the extent that motivational concerns seem to be the key to implementation, that is also the extent to which implementation is in the hands of the teachers 
and students and not in the bones of educational design (see Rohrer \& Hartwig, 2020; Zepeda, Martin, \& Butler, 2020.).

Motivational issues emerge strongly in Hodges and Lohse's (2020) analysis of motor learning, an area of research with a special place in the history of our thinking about desirable difficulties (e.g., Kerr \& Booth's, 1978, compelling example of varied practice in bean-bag tosses cited by Bjork, 1994). Hodges and Lohse carefully acknowledge the ways in which motor learning is affected by other factors that either question or contra-indicate applications of desirable difficulties, such as implicit learning and perception of success. Effortful learning, for example, is viewed by researchers in motor learning as a close cousin to desirable difficulty, and effortful learning implicates the sort of analytic deliberation that interferes with habitual (implicit?) learning. Hodges and Lohse attempt to reconcile such long standing motor-learning principles with the possible importance of desirable difficulties. For example, they call for evidence of improvements during practice, to preserve students' sense that achievement is possible. In motor learning, the perception of possible success is obviously essential...more blatantly but perhaps not more fundamentally important than in all the other settings represented in this forum.

Motivational issues, including the importance of perceptible success, are the explicit concerns of the final two essays. First, Finn (2020) cautions us to be mindful of more complex educational environments than those typically found in experimental research, by reviewing relevant research on classroom contexts, achievement motivation, and decision making. And she asks us to consider the effects of memory for previous similar experiences. In fact, maybe we should realize that some students simply prefer to treat some classes as ticket-punching opportunities, not because they choose not to learn but because they remember and value 
previous achievements with the old strategies. Finn asserts that the shaping of desirably difficult choices for learning depends importantly on remembering prior success with similar efforts. More generally, the application of desirable difficulties must consider students' goals, interests, and histories with variable educational contexts. This individualized approach has much in common with the developmental approach of Knabe and Vlach (2020) and with Hodges and Lohse's (2020) understanding of motor learning (and possibly with contingency management).

The last contribution to the forum (Zepeda, Martin, \& Butler, 2020) is really the first, because Andrew Butler provided a sounding board for organizing the forum. It merits the penultimate position by addressing explicit relations between research on motivation and research on desirable difficulties; the parallels are interesting. Just as learning strategies must consider the individual, the task, and the larger context (see McDaniel \& Butler, 2010), so too do strategies for motivating the tendency to engage with desirable difficulties. Zepeda et al. focus on strategies for increasing students' engagement and persistence. What are the strategies for finding meaning in a particular task; how can students and teachers increase interest; how can they come to see the task as important? The forum pauses on the consideration of these questions, as authors metaphorically await comments from Robert and Elizabeth Bjork (2020).

In summary of this preview, the contributions to the forum describe some impressive successes, but they also fully explore the obstacles and challenges of moving beyond the laboratory and classroom demonstrations of desirably difficult practices as we contemplate serious application of the science of learning and memory. The irony of this forum is that it is published in a time when going through the motions of learning might be at an all-time high, with Covid-19 introducing undesirable difficulties as we watch our educational systems make major allowances in order to punch tickets on time. Most immunologists believe we will beat 
Covid-19, and it is the job of applied cognitive scientists to rescue learning. I hope this forum gives us a boost, both now and in the future. 


\section{References}

Biwer, F., de Bruin, A. B. H., Schreurs, S., \& oude Egbrink, M. G. A. (2020). Future steps in teaching desirably difficult learning strategies: Reflections from the Study Smart program. Journal of Applied Research on Learning and Memory, 9, xxxx

Bjork, R. A. (1994). Memory and metamemory considerations in the training of human beings. In J. Metcalfe \& A.P. Shimamura (Eds). Metacognition: Knowing about knowing, 185-206. Cambridge, Mass: MIT Press.

Bjork, R. A., \& Bjork, E. L. (2020). Desirable difficulties in theory and practice. Journal of Applied Research on Learning and Memory, 9, xxxx

Bouton, M. E. (2000). A learning theory perspective on lapse, relapse, and the maintenance of behavior change. Health Psychology, 19, 57-63.

Carpenter, S. K., Witherby, A. E., \& Tauber, S. K.. (2020). On students' (mis)judgments of learning and teaching effectiveness. Journal of Applied Research on Learning and Memory, 9, 137-151.

Finn, B. (2020). Exploring interactions between motivation and cognition to better shape self-regulated learning. Journal of Applied Research on Learning and Memory, 9, xxxx

Hodges, N., \& Lohse, K. R. (2020). Difficulty is a real challenge: A perspective on the role of cognitive effort in motor skill learning. Journal of Applied Research on Learning and Memory, 9, $\mathrm{xxxx}$

Knabe, M. L., \& Vlach, H. A. (2020). When are difficulties desirable for children? Firtst steps toward a development and individual differences account of the spacing effect. Journal of Applied Research on Learning and Memory, 9, $\mathrm{xxxx}$ 
Kerr, R., \& Booth, B. (1978). Specific and varied practice of a motor skill. Perceptual and Motor Skills, 46, 395-401.

McDaniel, M. A., \& Butler, A. C. (2010). A contextual framework for understanding when difficulties are desirable. In A. S. Benjamin (Ed.), Successful remembering and successful forgetting: A festschrift in honor of Robert A. Bjork (pp. 175-198). New York:

Psychology Press.

Rohrer, D., \& Hartwig, M. K. (2020). Unanswered questions about spaced and interleaved mathematics practice. Journal of Applied Research on Learning and Memory, 9, xxxx

Schulze, L. N. (2020). Legal education's difficulty with “desirable difficulties” and its impact on student success and bar passage rates. Journal of Applied Research on Learning and Memory, 9, $\mathrm{xxxx}$

Wahlheim, C. N., \& Jacoby, L. L. (2013). Remembering change: The critical role of recursive remindings in proactive effects of memory. Memory \& Cognition, 41, 1-15.

Zepeda, C. D., Martin, R. S., \& Butler, A. C. (2020). Motivational strategies to engage learners in desirable difficulties. Journal of Applied Research on Learning and Memory, 9, xxxx 